\title{
AVALIAÇÃO DE EMISSÕES DE BIOGÁS EM CAMADAS DE COBERTURA DE UM ATERRO SANITÁRIO
}

\author{
Thyago Trocilo Araujo \\ Mestre em Engenharia Ambiental / UERJ \\ ttauff@gmail.com
}

\author{
Elisabeth Ritter \\ Doutora em Engenharia Civil / UERJ \\ ritteruerj@gmail.com
}

\section{RESUMO}

Os gases oriundos da biodegradação dos resíduos nos aterros sanitários provocam um sério problema de poluição atmosférica a níveis local e global. Nesse contexto, empregam-se os sistemas de cobertura que possuem dentre os seus objetivos, a retenção das emissões fugitivas de biogás para a atmosfera. A pesquisa foi realizada na fase de operação de um aterro sanitário e tem por objetivo comparar as emissões fugitivas de biogás, enfocando o metano, em três sistemas de cobertura construídos em célula experimental: convencional, barreira capilar e evapotranspirativa. As investigações de campo consistiram em ensaios de placa de fluxo para mensurar a composição do biogás e o fluxo pelas camadas de cobertura. Os resultados indicaram que as emissões de biogás na camada convencional variaram de 7,5 a $389,0 \mathrm{~g} / \mathrm{m}^{2}$.dia para o $\mathrm{CH}_{4}$. $\mathrm{Na}$ camada de barreira capilar, as emissões de $\mathrm{CH}_{4}$ variaram de 7,2 a $369,2 \mathrm{~g} / \mathrm{m}^{2}$.dia A camada evapotranspirativa proporcionou o melhor desempenho em relação às demais camadas de cobertura, apresentando variação de 5,0 a $68,9 \mathrm{~g} / \mathrm{m}^{2}$.dia para as emissões de $\mathrm{CH}_{4}$. A vegetação neste tipo de cobertura mostrou-se um fator decisivo para a proteção da camada, reduzindo as emissões de biogás para a atmosfera.

Palavras-chave: Aterro sanitário; Camada evapotranspirativa; Barreira capilar; Fluxo de gás.

\begin{abstract}
The gases from the waste biodegradation in landfills cause a serious problem of local air pollution and global levels. In this context, are employed in the cover systems that have among its objectives, the retention of biogas fugitive emissions to the atmosphere. The research was conducted in the landfill operating phase and aims to compare the fugitive emissions of biogas, methane, focusing on three cover systems built on experimental cell: conventional, capillary barrier and evapotranspirative cover. The field investigations were done with the flow chamber tests to measure biogas composition and flow through the layers of coverage. The results indicated that biogas emissions in conventional layer ranged from 7,5 to $389,0 \mathrm{~g} / \mathrm{m}^{2}$.dia for $\mathrm{CH}_{4}$. In capillary barrier layer, $\mathrm{CH}_{4}$ emissions ranged from 7,2 to $369,2 \mathrm{~g} / \mathrm{m}^{2}$.dia. The evapotranspiration cover provided the best performance in relation to other covers systems with varying from 5,0 to $68,9 \mathrm{~g} / \mathrm{m}^{2}$.dia for $\mathrm{CH}_{4}$. The vegetation in this type of system proved to be a decisive factor for the protection cover by reducing emissions of biogas to the atmosphere.
\end{abstract}

Keywords: Landfill; Evapotranspiration layer; Capillary barrier; Gas flow. 


\section{INTRODUÇÃO}

A disposição final de resíduos sólidos urbanos deve ser realizada em aterro sanitário, que é uma obra de engenharia projetada com critérios técnicos, onde a disposição dos resíduos no solo minimize os impactos ambientais e os danos à saúde pública. Desta forma, é fundamental que haja monitoramento ambiental e geotécnico durante a sua implantação, operação e encerramento.

Os aterros sanitários podem ser considerados grandes reatores bioquímicos, tendo como principais matérias prima os resíduos sólidos e a água pluvial e como produtos o lixiviado e os gases que precisam ser monitorados, tratados e/ou aproveitados (TCHOBANOGLOUS et al., 1993).

Em Dezembro de 2015, foi assinado o Acordo de Paris no âmbito da Convenção - Quadro das Nações Unidas sobre a Mudança do Clima, visando à adoção de uma economia de baixo carbono até o fim deste século. Dentre os objetivos da convenção, está o de promover o baixo desenvolvimento de emissões de gases de efeito estufa. Neste acordo, o Brasil se compromete a reduzir as emissões de gases de efeito estufa em $37 \%$ até 2025.

Os gases gerados pela biodegradação dos resíduos sólidos em aterros sanitários são compostos majoritariamente por metano $\left(\mathrm{CH}_{4}\right)$ e gás carbônico $\left(\mathrm{CO}_{2}\right)$, sendo esses gases os principais responsáveis pelo aquecimento global. Uma parcela desses gases, também chamado de biogás, ultrapassa as camadas de cobertura e escapa para a atmosfera, mesmo quando o aterro sanitário apresenta um sistema de captação de biogás.

Os sistemas de cobertura dos resíduos sólidos urbanos atuam na minimização da liberação de biogás para a atmosfera e, podem ser constituídos de camadas diaria, intermediária ou final. Em aterros de grande porte, em função de questões operacionais, muitas vezes as camadas intermediárias ficam expostas por 2 ou 3 anos até receberem os resíduos novamente. Estas camadas não tem o controle de execução de uma camada final, portanto, medir as emissões nestas camadas tem relevância. Cada sistema de cobertura está associado a problemas potenciais, portanto, cada aterro sanitário terá a sua particularidade na escolha do tipo de cobertura a ser adotada de forma que atendam as funções requeridas para os quais foi proposto.

No Brasil, a maioria dos aterros possui cobertura com camada homogênea de solo compactado, de preferência usando solos argilosos. Entretanto, pesquisas têm sido realizadas com a utilização de camadas que diferenciam das convencionais (CABRAL et al., 2007; FERNANDES, 2009; PARK et al., 2009; LOPES, 2011).

A pesquisa foi desenvolvida a partir da necessidade do controle das emissões de biogás, reduzindo a possibilidade de instabilidade dos aterros, minimizando a migração de gases pela fundação do aterro e emissões atmosféricas, além de gerar energética para o uso direto dentro dos aterros sanitários.

Dentro deste contexto, este trabalho teve o objetivo de avaliar as emissões de biogás, enfocando o metano, em camadas de cobertura do tipo convencional, barreira capilar e evapotranspirativa, implantadas em células experimentais de um aterro sanitário de grande porte.

\section{METODOLOGIA}

\subsection{Local de estudo}

O local escolhido para a realização do estudo foi uma área dentro de um aterro sanitário de grande porte que recebe os resíduos sólidos urbanos provenientes de 3 municípios e iniciou as operações em abril de 2011. A topografia do local onde se situa o aterro sanitário favorece a operação do mesmo, visto que se constitui de grande área plana, tendo disponibilidade de jazidas de solos, que são utilizados nos sistemas de cobertura. Atualmente, o aterro sanitário recebe uma média de 10 mil toneladas por dia de resíduos dispostos.

A pesquisa foi conduzida em células experimentais localizadas na área conhecida como sub-aterro 01 com altura de resíduos aproximada de 70,0 metros. Os resíduos foram dispostos nesta localidade de 2011 a 
2013, onde desde então, a área não recebeu mais resíduos. O sistema de captação de biogás estava inativo durante todo o período do estudo, sendo composto por 80 poços de extração passiva. A Figura 1 ilustra a visão geral do aterro sanitário, destacando o sub-aterro 01 e o local do experimento.



Figura 1: Visão geral do aterro sanitário Fonte: Google earth (2016)

A região se caracteriza por condições climáticas que a classificam como de clima subtropical a tropical chuvoso, apresentando um inverno seco e verão quente. Registros históricos entre 1995 e 2004 indicam médias de precipitação de $50 \mathrm{~mm}$ para julho e $300 \mathrm{~mm}$ para janeiro. A Figura 2 apresenta o índice pluviométrico mensal para os anos de 2013, 2014, 2015 e 2016 (até abril) obtidos a partir de uma Estação Meteorológica Automática próxima, operada pelo INMET. Verifica-se que o período de precipitação pluviométrica máxima vai de novembro a março e o de precipitação pluviométrica mínima, de abril a outubro. O mês mais seco é agosto, com uma precipitação média de $23 \mathrm{~mm} /$ ano e o mês mais chuvoso é janeiro, com precipitação média de $241 \mathrm{~mm} / \mathrm{ano}$. A precipitação anual varia entre $931 \mathrm{~mm} /$ ano a 1.475 $\mathrm{mm} /$ ano. $\mathrm{O}$ ano de 2015 foi caracterizado como um período seco, visto que a precipitação anual foi de 688 $\mathrm{mm}$ frente os $1.475 \mathrm{~mm}$ encontrados para o ano de 2013. Para o ano de 2016, a precipitação média mensal até o mês de abril foi de $505 \mathrm{~mm}$, mostrando que para este ano as precipitações foram superiores aquelas encontradas nos anos de 2014 e 2015.



Figura 2: Precipitação mensal de janeiro de 2013 a abril de 2016 na Estação Meteorológica Automática 


\subsection{Descrição do experimento de campo}

O experimento consiste de 4 células com camadas experimentais construídas por Joaquim Jr. (2015), cada qual com as dimensões de 4,0 $\mathrm{m} \mathrm{x} \mathrm{7,0} \mathrm{m,} \mathrm{totalizando} 28,0 \mathrm{~m}^{2}$ de área, possuindo um espaçamento de 4,0 m entre si. A Figura 3 apresenta o desenho esquemático da disposição das células experimentais.

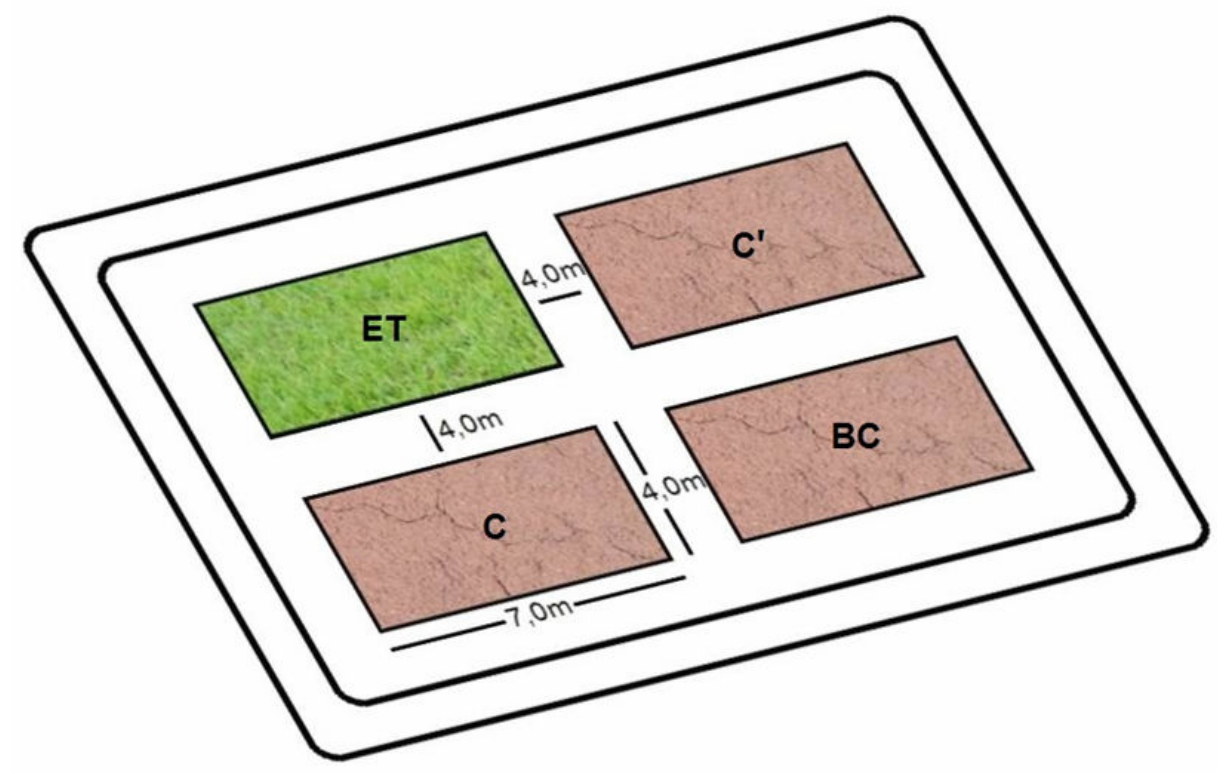

Figura 3: Esquema (sem escala) da disposição das células experimentais

Legenda: $\mathrm{C}_{\text {e }} \mathrm{C}^{\prime}=$ convencional; $\mathrm{BC}=$ barreira capilar; $\mathrm{ET}=$ evapotranspirativa

As configurações do projeto das camadas de cobertura são:

- Camada Convencional (C): camada compactada de 0,50 m de solo da jazida (A) local (denominado solo "A");

- Camada Convencional (C'): camada compactada de 0,50 m de solo da jazida (B) local (denominado solo "B");

- Barreira Capilar (BC): camada de 0,20 m de brita, sobreposta por uma manta geotêxtil não tecido de 400 $\mathrm{g} / \mathrm{m}^{2}$, seguida de uma camada de $0,40 \mathrm{~m}$ de areia e por fim uma camada de 0,50 $\mathrm{m}$ de solo da jazida (A) local;

- Evapotranspirativa (ET): camada de 0,50 m de solo da jazida (A) local, seguida de uma cobertura vegetal de grama do tipo "esmeralda".

Observa-se que os solos "A" e "B" possuem destinações distintas dentro do aterro sanitário. Enquanto o solo "A" é geralmente empregado nas coberturas intermediárias, o solo "B" é destinado à camada de cobertura final. Em decorrência da diferente aplicabilidade, ambos os solos foram estudados em relação às emissões de biogás.

A Figura 4 ilustra esquematicamente as configurações das coberturas que compõem o experimento. Como as configurações da camada convencional (C) e da camada convencional (C') são similares, representaram-se as mesmas em um único perfil esquemático. 


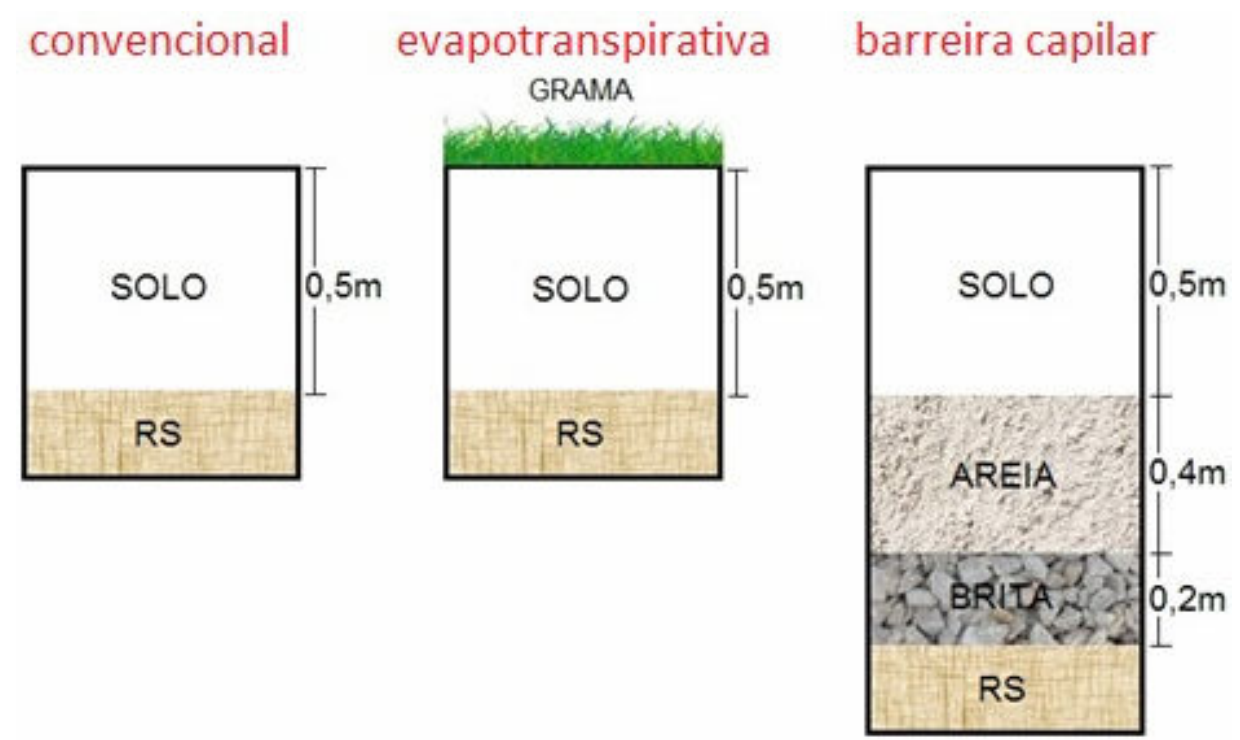

Figura 4: Esquema do perfil das camadas de cobertura do experimento

\subsection{Caracterização dos solos utilizados nas camadas de cobertura}

Em relação à característica geotécnica do solo "A", este foi caracterizado como uma areia siltoargilosa com $60 \%$ de areia, $30 \%$ de silte e $10 \%$ de argila, com limite de liquidez de $56,5 \%$, índice de plasticidade de $22,1 \%$ e peso específico das partículas de $27,5 \mathrm{kN} / \mathrm{m}^{3}$. O ensaio de Proctor Normal indicou massa específica seca de $15,19 \mathrm{kN} / \mathrm{m}^{3}$ e uma umidade ótima de $23,5 \%$.

O solo "B" apresentou 50\% de teor de areia, um pouco menor do que o solo "A" e $8 \%$ de teor de argila, similar ao solo "A". Destaca-se que o solo "B" teve a presença de $4 \%$ de pedregulho enquanto que o solo "A" não teve a presença de tal granulometria. O limite de liquidez foi de $49,7 \%$, índice de plasticidade de $27,8 \%$ e peso específico das partículas de $27,4 \mathrm{kN} / \mathrm{m}^{3}$. O ensaio de Proctor Normal indicou massa específica seca de $17,03 \mathrm{kN} / \mathrm{m}^{3}$ e uma umidade ótima de $18,8 \%$. Os resultados granulométricos obtidos para os teores de argila, silte e areia fizeram com que o solo "B" fosse classificado como areia siltosa (SM), assim como o solo "A".

Joaquim Jr. (2015) realizou ensaios pontuais em cada uma das células experimentais para a determinação do grau de compactação dos solos das camadas de cobertura. Os resultados mostraram que a camada convencional com o solo "A" obteve um grau de compactação de $92 \%$ enquanto que a camada convencional com solo "B" obteve grau de compactação de $88,2 \%$. Destaca-se que a camada com solo "B" foi construída um ano após as demais camadas de cobertura. A camada evapotranspirativa apresentou o menor grau de compactação, que foi de $72,2 \%$. Este resultado pode estar associado à ação das raízes da vegetação que contribui para a diminuição da compactação, visto que o ensaio foi realizado bem próximo à superfície do terreno, onde atua a vegetação. A camada de barreira capilar obteve resultado de $86,9 \%$ para o grau de compactação.

\subsection{Ensaios de campo}

Os ensaios de campo foram realizados de agosto de 2014 a fevereiro de 2016, representando um total de 22 investigações de campo. Destaca-se que o período foi caracterizado como seco, com baixas precipitações, exceto os meses de novembro e dezembro de 2015 e janeiro e fevererio de 2016 que tiveram precipitações acima de $100 \mathrm{~mm}$. Em função das dificuldades encontradas para a realização dos mesmos em dias chuvosos, todos os ensaios de campo foram realizados em dias sem chuva, com temperaturas variando de 24,0 a $41,0{ }^{\circ} \mathrm{C}$. As maiores temperaturas $\left(35\right.$ a $\left.41^{\circ} \mathrm{C}\right)$ foram aferidas nos ensaios realizados nos meses de dezembro de 2014 e janeiro de 2015 . Já as menores temperaturas $\left(24\right.$ a $\left.25^{\circ} \mathrm{C}\right)$ foram medidas nos ensaios do mês de outubro de 2015 .

As determinações dos fluxos de gases oriundos dos sistemas de cobertura foram realizadas 
utilizando-se a metodologia do ensaio de placa de fluxo estática (MACIEL, 2003; MARIANO, 2008; TEIXEIRA et al., 2009; LOPES, 2011).

Foram utilizadas duas placas de fluxo nas investigações de campo. Uma das placas de fluxo foi construída com chapa de aço galvanizado de $2 \mathrm{~mm}$ de espessura e topo em acrílico cristal com $8 \mathrm{~mm}$ de espessura, possuindo dimensões de $0,16 \mathrm{~m}^{2}$ de área e $8,3 \mathrm{~L}$ de volume, similar as utilizadas nas pesquisas de Maciel (2003) e Oliveira (2013). A outra placa de fluxo foi construída com aço inox, possuindo dimensões de $1 \mathrm{~m}^{2}$ de área e 50,0 L de volume. A escolha de uma placa maior foi para ter uma área de abrangência maior para as fissuras presentes no solo dos sistemas de cobertura. Ambas as placas foram cravadas no solo de cobertura, tendo suas extremidades seladas com solo e água para que não houvesse o escape do biogás para a atmosfera. Após a etapa de cravação, os equipamentos utilizados nos ensaios foram conectados a placa de fluxo. A Figura 5 ilustra as etapas de instalação da placa de fluxo de $1 \mathrm{~m}^{2}$ e dos respectivos equipamentos de leituras utilizados nos ensaios de campo.

A escolha inicial para a instalação da placa de fluxo foi baseada em pontos providos de rachaduras e fendas (fissuras) na área das células experimentais, onde o escape do biogás é preferencial.

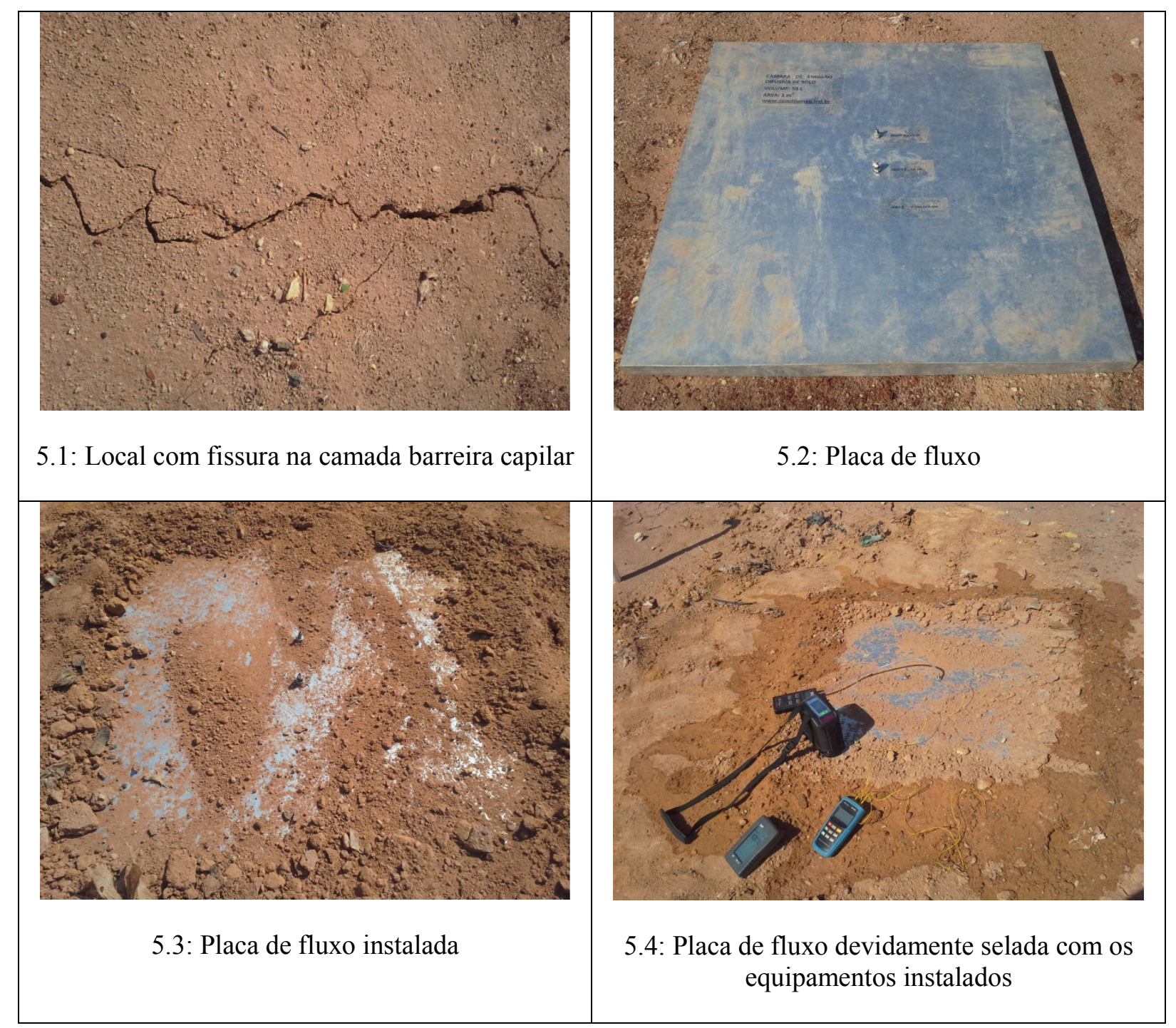

Figura 5: Etapas da instalação da placa de fluxo e dos equipamentos de leitura nos ensaios de campo 
As leituras das concentrações dos gases foram realizadas com a utilização do detector portátil Dräger X-am 7000 que detecta simultaneamente e de forma contínua até 5 (cinco) gases: $\left(\mathrm{CH}_{4}, \mathrm{CO}_{2}, \mathrm{CO}, \mathrm{H}_{2} \mathrm{~S}\right.$ e $\left.\mathrm{O}_{2}\right)$. Além disso, foram realizadas medições de pressão e temperaturas internas e externas a placa ao longo do tempo do ensaio.

O intervalo das leituras das concentrações dos gases foi de 5 minutos para a placa menor. Já para a placa maior, adotaram-se intervalos de 2 minutos até o oitavo minuto e, posteriormente em intervalos de 4 minutos até o minuto final. A duração dos ensaios de ambas as placas de fluxo foram de 60 minutos.

O fluxo de gás $(J)$ foi determinado a partir dos resultados obtidos nos ensaios de placa de fluxo estática por meio da equação 1: CZEPIEL et al. (1996).

$J=\left[\left(V_{p} \times \rho\right) / A\right] \times(\Delta C / \Delta t)$

Onde $\mathrm{J}$ representa o fluxo de gás $\left(\mathrm{kg} / \mathrm{m}^{2} . \mathrm{s}\right) ; \mathrm{V}_{\mathrm{p}}$ é o volume útil da placa de fluxo $\left(\mathrm{m}^{3}\right) ; \mathrm{A}$ é a área de solo coberta pela placa $\left(\mathrm{m}^{2}\right) ; \rho$ é a massa específica do gás a determinada temperatura $\left(\mathrm{kg} / \mathrm{m}^{3}\right) ; \Delta \mathrm{C} / \Delta \mathrm{t}$ é a variação da concentração do gás (\% vol) com o tempo (s).

\section{RESULTADOS E DISCUSSÃO}

\subsection{Emissões de biogás}

Conforme já dito, mesmo com todas as impossibilidades encontradas para a realização de ensaios em tempo chuvoso, o período no qual está compreendida a pesquisa foi caracterizado por baixas precipitações, principalmente no verão de 2015 onde as precipitações nos meses de janeiro e março foram de $4 \mathrm{~mm}$ e $3 \mathrm{~mm}$ respectivamente.

A Tabela 1 apresenta um resumo dos resultados obtidos para as emissões de $\mathrm{CH}_{4}$ e $\mathrm{CO}_{2}$ conjuntamente com a caracterização dos pontos em relação à existência de fissuras no momento dos ensaios de campo. fissuras

Tabela 1: Resumo das emissões de $\mathrm{CH}_{4} \mathrm{e} \mathrm{CO}_{2}$ e caracterização dos pontos em relação à existência de

\begin{tabular}{cccccc}
\hline Ponto & Data & $\begin{array}{c}\text { Fluxo de CH} \\
\left(\mathbf{g} / \mathbf{m}^{2} \mathbf{. d i a}\right)\end{array}$ & $\begin{array}{c}\text { Fluxo de CO } \\
\left(\mathbf{g} / \mathbf{m}^{2} \text {.dia) }\right.\end{array}$ & Placa & $\begin{array}{c}\text { Presença de } \\
\text { Fissuras no ensaio }\end{array}$ \\
\hline C'1 & $07 / 08 / 2014$ & 105,1 & 291,5 & PP & Sim (pequena) \\
BC1 & $13 / 11 / 2014$ & 349,5 & 961,3 & PP & Sim (média) \\
C1 & $13 / 11 / 2014$ & 8,2 & 29,0 & PP & Não \\
ET1 & $13 / 11 / 2014$ & 8,8 & 36,5 & PP & Não \\
C'2 & $27 / 11 / 2014$ & 389,0 & 843,4 & PG & Sim (grande) \\
ET2 & $27 / 11 / 2014$ & 49,8 & 111,3 & PG & Não \\
BC2 & $16 / 12 / 2014$ & 369,2 & 855,1 & PG & Sim (média) \\
C2 & $16 / 12 / 2014$ & 29,9 & 65,8 & PG & Sim (grande) \\
ET3 & $16 / 12 / 2014$ & 5,0 & 47,7 & PG & Não \\
BC3 & $16 / 01 / 2015$ & 86,0 & 278,3 & PG & Sim (pequena)
\end{tabular}




\section{PERSPECTIVAS online}

$\begin{array}{cccccc}\text { C3 } & 16 / 01 / 2015 & 14,0 & 69,5 & \text { PG } & \text { Sim (grande) } \\ \text { BC4 } & 26 / 01 / 2015 & 7,2 & 37,4 & \text { PG } & \text { Sim (pequena) } \\ \text { C4 } & 26 / 01 / 2015 & 7,5 & 32,4 & \text { PG } & \text { Sim (pequena) } \\ \text { C5 } & 10 / 02 / 2015 & 9,3 & 30,1 & \text { PG } & \text { Não } \\ \text { ET5 } & 10 / 02 / 2015 & 43,3 & 93,5 & \text { PG } & \text { Não } \\ \text { C'3 } & 01 / 09 / 2015 & 64,6 & 115,6 & \text { PG } & \text { Não } \\ \text { BC5 } & 01 / 09 / 2015 & 67,5 & 247,5 & \text { PG } & \text { Sim (pequena) } \\ \text { BC6 } & 22 / 10 / 2015 & 51,0 & 167,5 & \text { PG } & \text { Sim (pequena) } \\ \text { C6 } & 22 / 10 / 2015 & 14,7 & 125,0 & \text { PG } & \text { Sim (pequena) } \\ \text { BC7 } & 03 / 02 / 2016 & 66,8 & 86,4 & \text { PG } & \text { Sim (pequena) } \\ \text { C'4 } & 03 / 02 / 2016 & 106,7 & 326,3 & \text { PG } & \text { Sim (pequena) } \\ \text { ET6 } & 03 / 02 / 2016 & 68,9 & 207,6 & \text { PG } & \text { Não }\end{array}$

PP - placa pequena; PG - placa grande

Observa-se na Tabela 1 que nos pontos da camada evapotranspirativa há a omissão do ponto ET4 na sequência cronológica. Este fato ocorreu em consequência do comportamento atípico nas variações das concentrações dos gases durante o ensaio ET4, sugerindo que pode ter havido entrada de $\mathrm{O}_{2}$ na placa de fluxo. cobertura.

A figura 6 apresenta exemplos de fissuras classificadas como grande e pequena nas camadas de



Figura 6.1: Ensaio C2

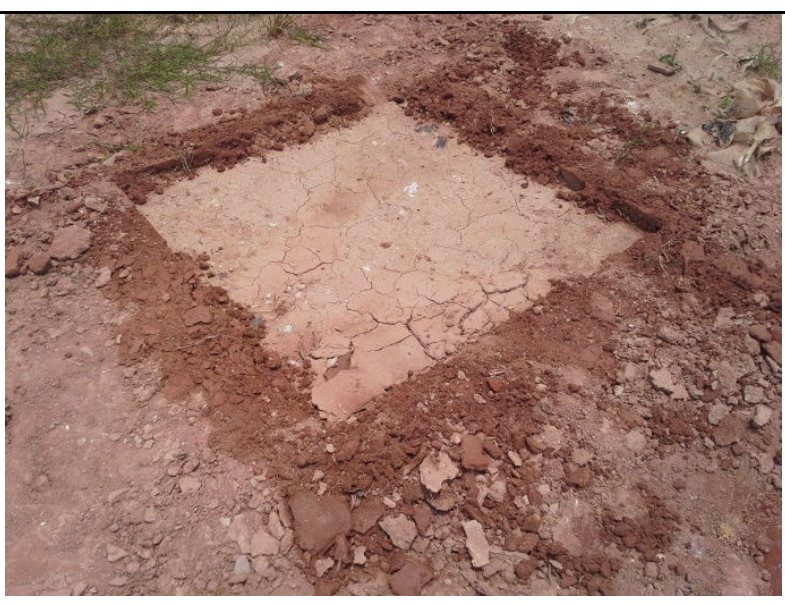

Figura 6.2: Ensaio C4

Figura 6: Exemplos de fissuras grande e pequena no solo de cobertura

A Figura 7 apresenta o gráfico com os resultados obtidos para as emissões de $\mathrm{CH}_{4}$ medidas em $\mathrm{g} / \mathrm{m}^{2}$.dia, para os três tipos de camadas de cobertura estudados. 




Figura 7: Emissões de $\mathrm{CH}_{4}$ pelas camadas de cobertura

Observa-se que as emissões de $\mathrm{CH}_{4}$ nas camadas de cobertura convencional (C) e evapotranspirativa (ET) se concentraram na faixa de 5,0 a $70,0 \mathrm{~g} / \mathrm{m}^{2}$.dia. Já nas camadas convencional (C') e barreira capilar (BC) houve maior dispersão nas emissões de $\mathrm{CH}_{4}$, apresentando valores na faixa de 7,0 a $390,0 \mathrm{~g} / \mathrm{m}^{2}$.dia. Porém, a maioria dos resultados obtidos nestas duas camadas se concentraram na faixa de 7,0 a 110,0 $\mathrm{g} / \mathrm{m}^{2}$.dia, apresentando valores que são 1,6 vezes superiores aos encontrados nas camadas C e ET.

As emissões de biogás também foram comparadas separadamente em relação à existência de fissuras nos pontos em que foram realizados os ensaios de placa de fluxo.

Os resultados das emissões de $\mathrm{CH}_{4}$ em pontos que continham fissuras nas camadas de cobertura são apresentados na Figura 8.

O ensaio C'2 apresentou o maior fluxo de $\mathrm{CH}_{4}$, que foi de $389,0 \mathrm{~g} / \mathrm{m}^{2}$.dia, com fissura de grande porte. Os ensaios $\mathrm{BC} 1$ e BC2 apresentaram valores para o fluxo de $\mathrm{CH}_{4}$ similares, sendo de $249,5 \mathrm{~g} / \mathrm{m}^{2}$.dia e $369,2 \mathrm{~g} / \mathrm{m}^{2}$.dia respectivamente. Mesmo as fissuras dos ensaios BC1 e BC2 tendo sido caracterizadas como de médio porte, foi verificado que a profundidade da fissura alcançava a camada de areia da barreira capilar. Desta forma, a emissão fugitiva foi facilitada pela elevada permeabilidade ao ar da areia.

Observa-se que, apesar das fissuras terem sido caracterizadas como grandes nos ensaios C2 e C3, os valores encontrados para o fluxo de $\mathrm{CH}_{4}$ foram insignificantes quando comparado com o ensaio C'2, que teve a mesma caracterização quanto ao tamanho da fissura. Conforme já mencionado, o grau de compactação da camada $C$ foi de $92 \%$ enquanto da C' $88 \%$ no dia da determinação de campo indicando uma condição melhor. 


\section{Fluxo de CH4}

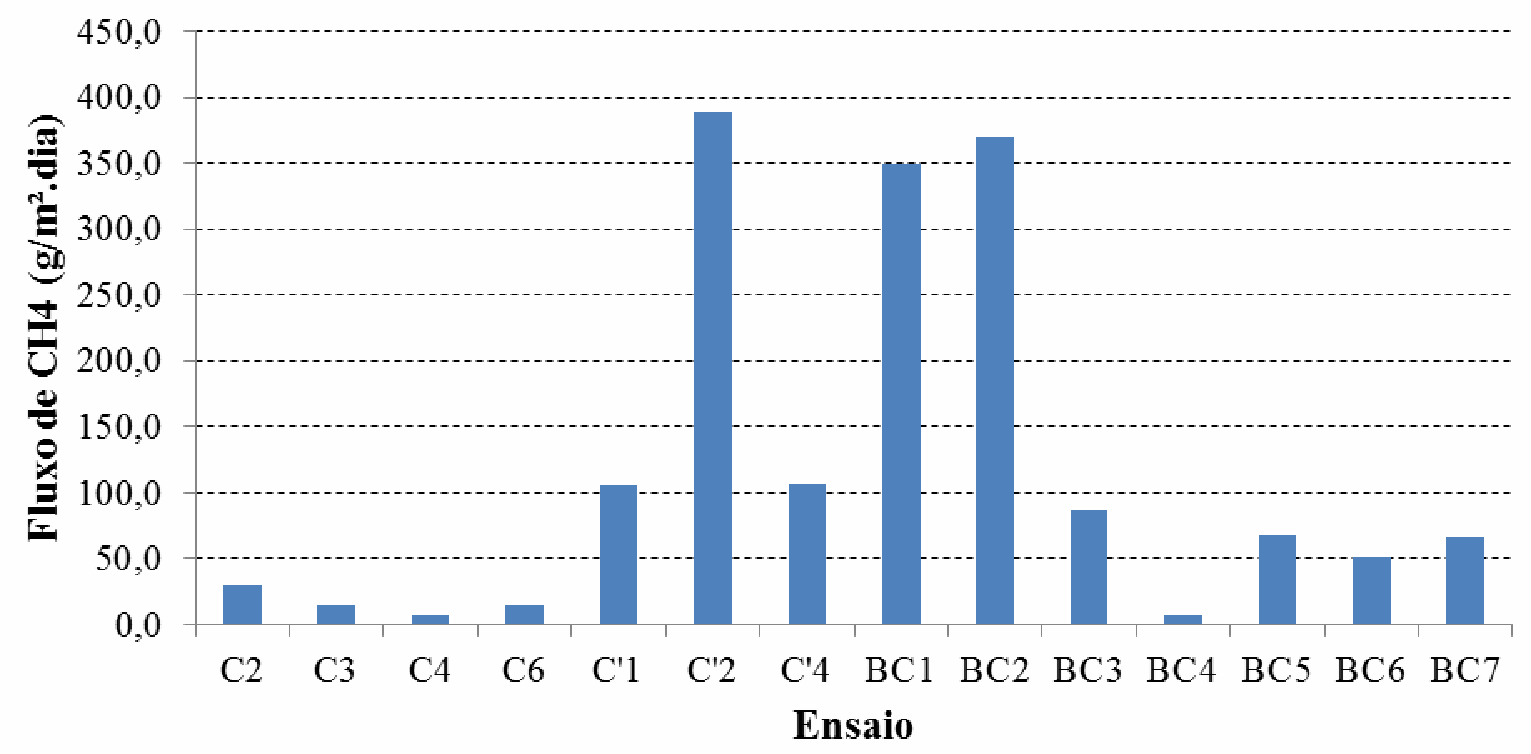

Figura 8: Fluxos de $\mathrm{CH}_{4}$ nos ensaios que continham fissuras

Os resultados das emissões de $\mathrm{CH}_{4}$ em pontos que não continham fissuras nas camadas de coberturas são apresentados na Figura 9.

Comparando os resultados encontrados nos ensaios das camadas convencionais nos pontos sem fissuras, o ensaio C'3 apresentou o maior fluxo de $\mathrm{CH}_{4}\left(64,6 \mathrm{~g} / \mathrm{m}^{2}\right.$.dia), sendo 7,9 vezes superior ao menor fluxo de $\mathrm{CH}_{4}$, representado pelo ensaio $\mathrm{C} 1\left(8,2 \mathrm{~g} / \mathrm{m}^{2}\right.$.dia).

\section{- Fluxo de $\mathrm{CH} 4$}

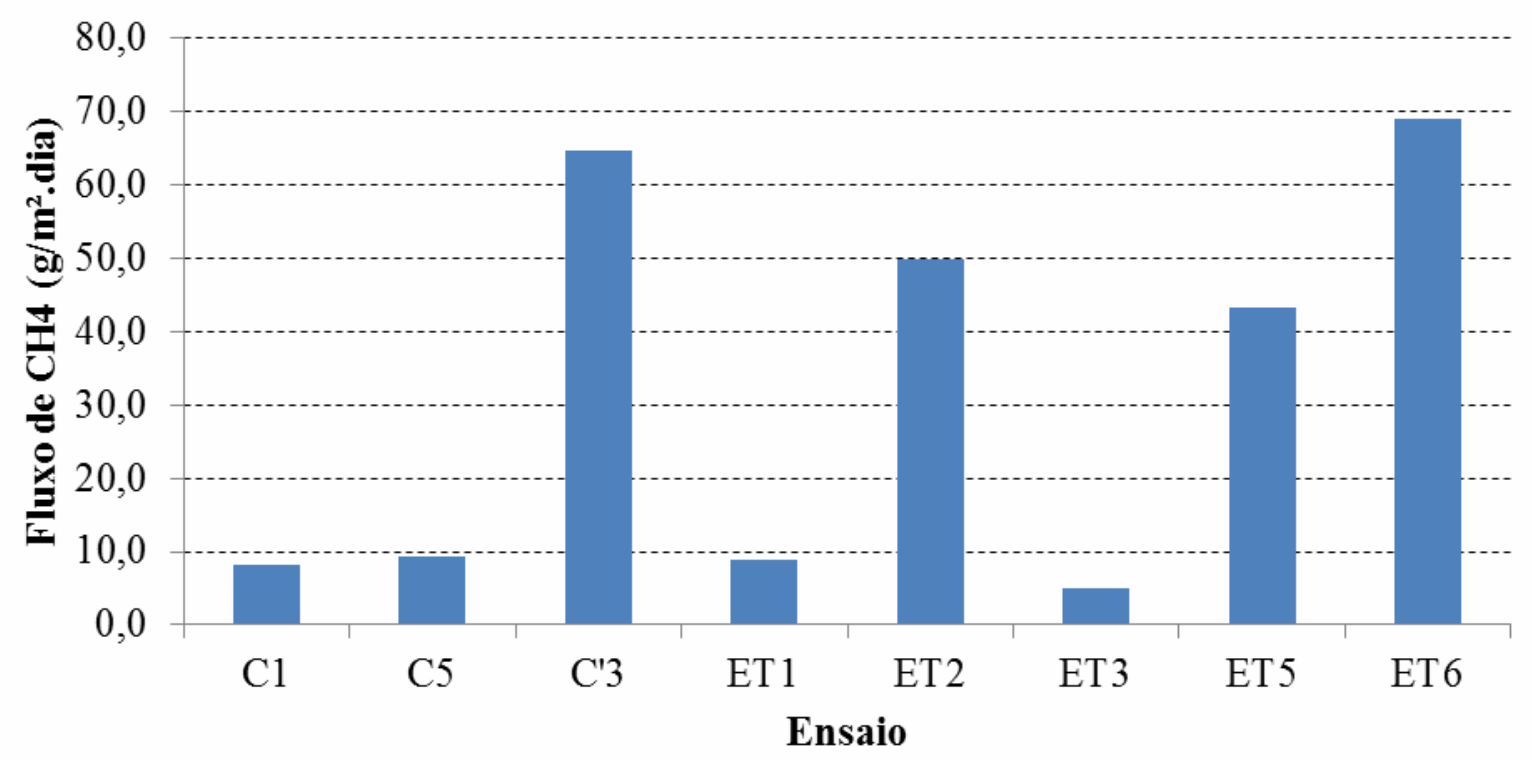

Figura 9: Fluxos de $\mathrm{CH}_{4}$ nos ensaios que não continham fissuras 
O ensaio ET6 apresentou o maior fluxo de $\mathrm{CH}_{4}$, que foi de $68,9 \mathrm{~g} / \mathrm{m}^{2}$.dia. Destaca-se que neste ensaio, a camada evapotranspirativa estava bastante depreciada em função do número de ensaios realizados, das condições climáticas e operacionais do aterro anitário. A Figura 10 mostra a situação da vegetação nos ensaios ET2 e ET5, realizados em 27/11/2014 e 03/02/2016 respectivamente.

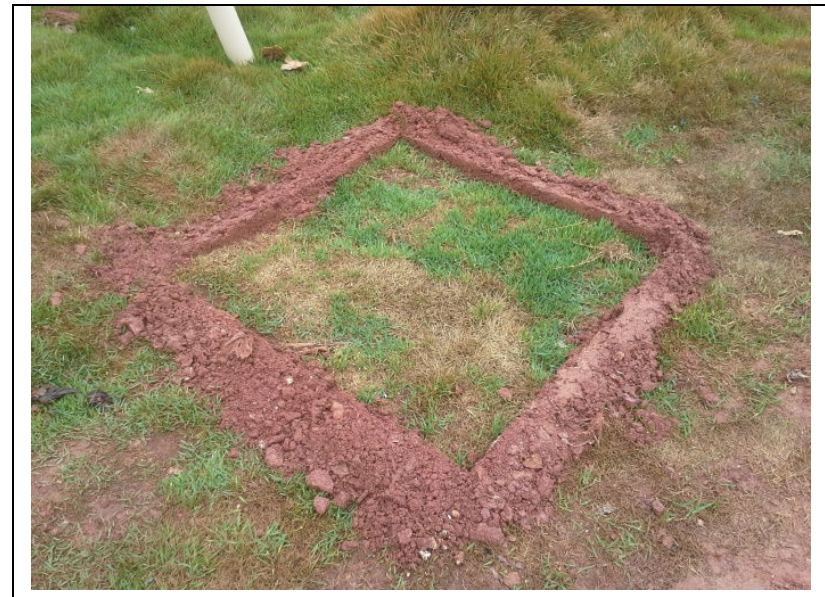

Figura 10.1: Ensaio ET2

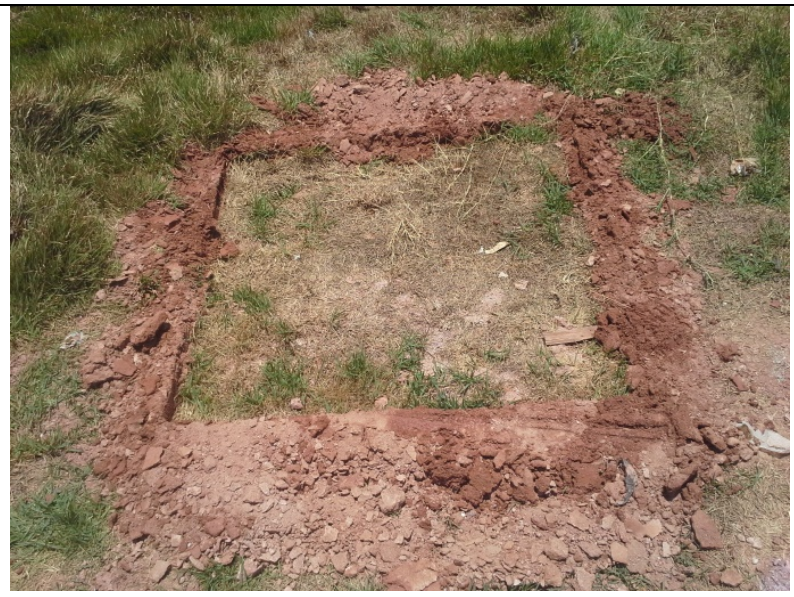

Figura 10.2: Ensaio ET5

Figura 10: Característica física da vegetação nos ensaios ET2 e ET5

A Figura 11 apresenta o gráfico com os resultados obtidos para as emissões de $\mathrm{CO}_{2}$ medidas em $\mathrm{g} / \mathrm{m}^{2}$.dia, para os três tipos de camadas de cobertura estudados.

As variações das emissões de $\mathrm{CO}_{2}$ ficaram no intervalo de 30,0 a $210,0 \mathrm{~g} / \mathrm{m}^{2}$.dia nas camadas convencional (C) e evapotranspirativa (ET) e de 37,0 a $962,0 \mathrm{~g} / \mathrm{m}^{2}$.dia nas camadas convencional (C') e barreira capilar $(\mathrm{BC})$.

$\square \mathrm{C} \square \mathrm{C}^{\prime} \bullet \mathrm{BC} \Delta \mathrm{ET}$

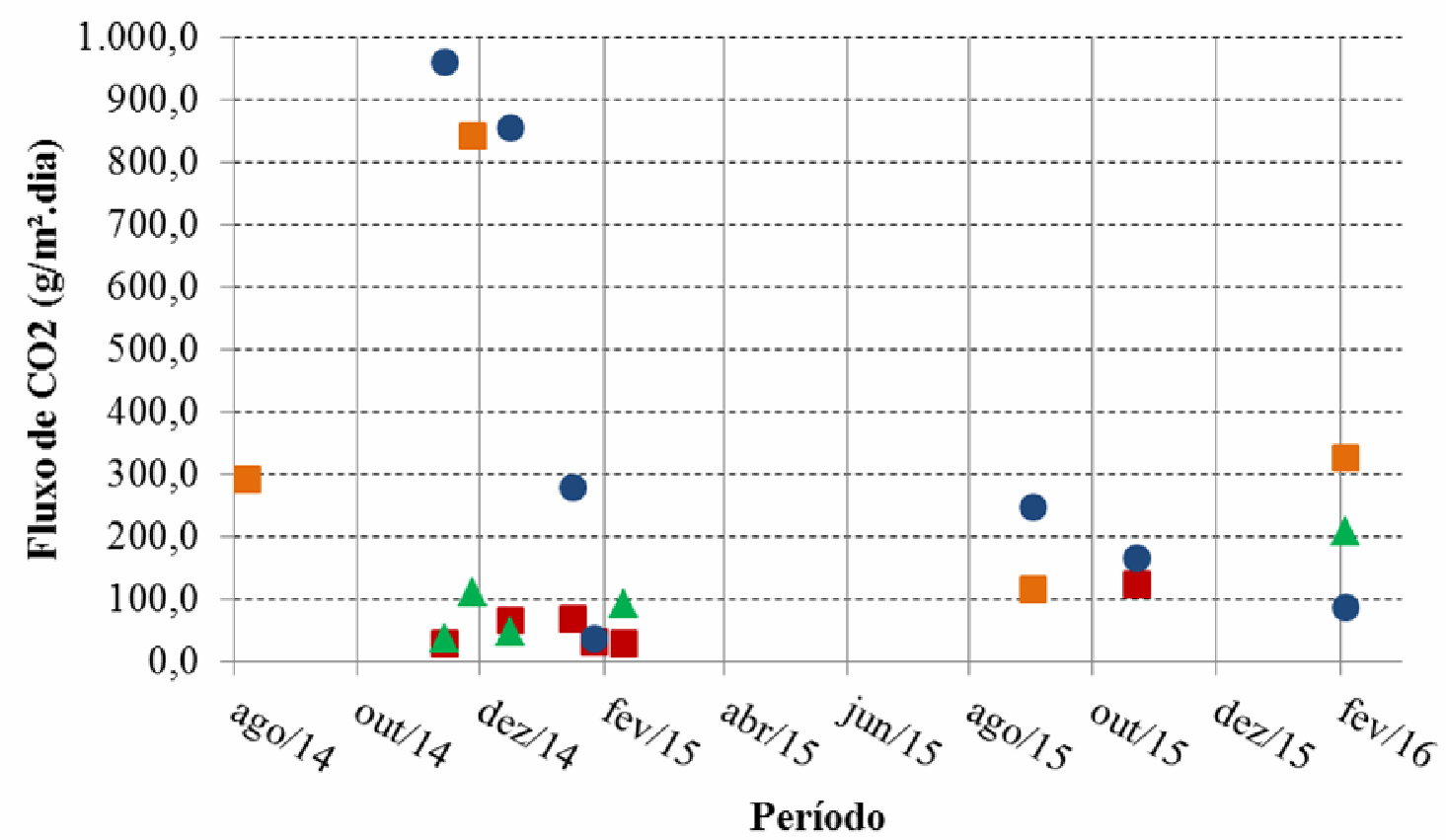


Figura 11: Emissões de $\mathrm{CO}_{2}$ pelas camadas de cobertura

As emissões de $\mathrm{CO}_{2}$ nos pontos que continham fissuras nas camadas de coberturas são apresentadas na Figura 12 e as emissões nos pontos sem fissuras são apresentadas na Figura 13.

\section{Fluxo de $\mathrm{CO} 2$}

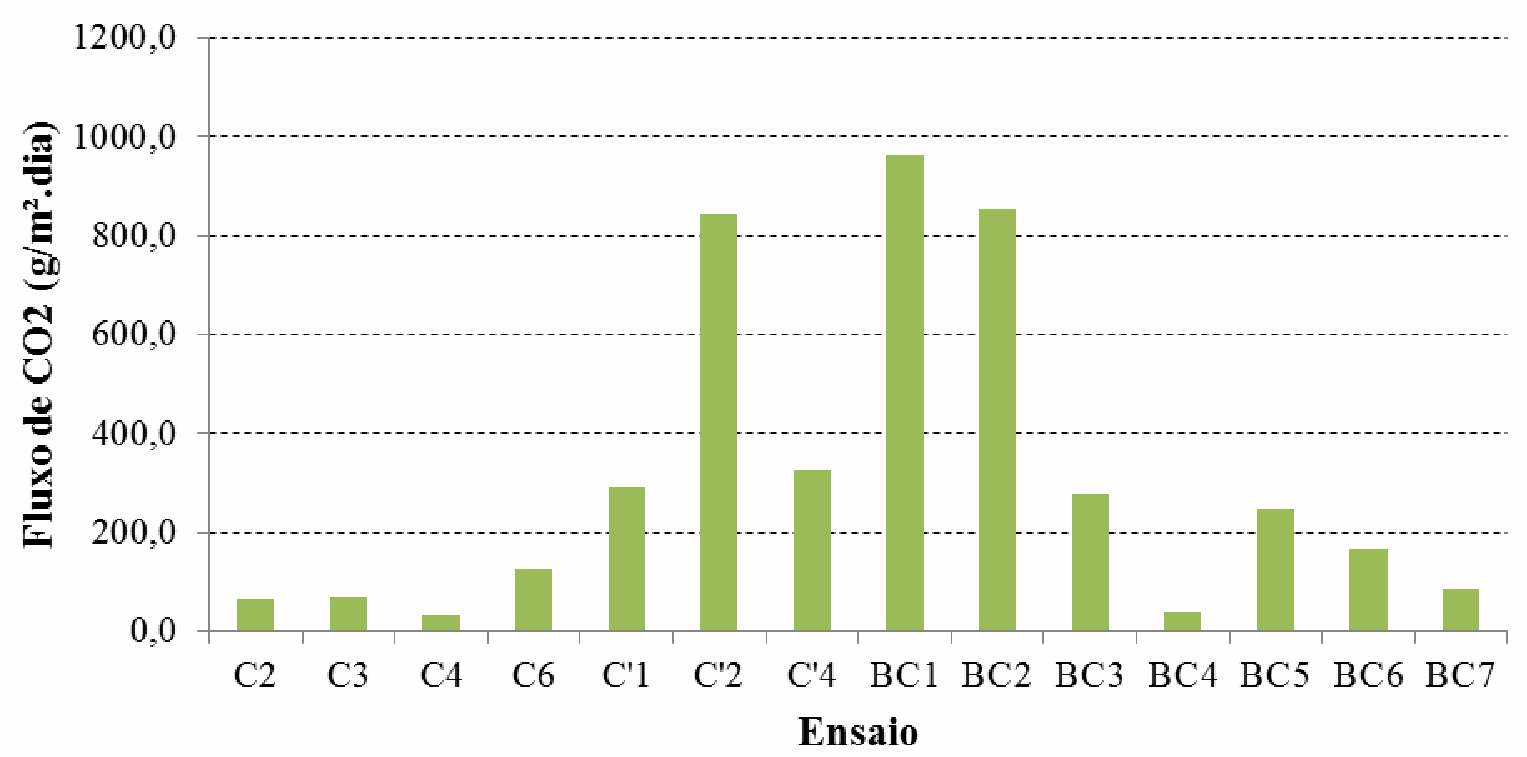

Figura 12: Fluxos de $\mathrm{CO}_{2}$ nos ensaios que continham fissuras

\section{Fluxo de $\mathrm{CO} 2$}

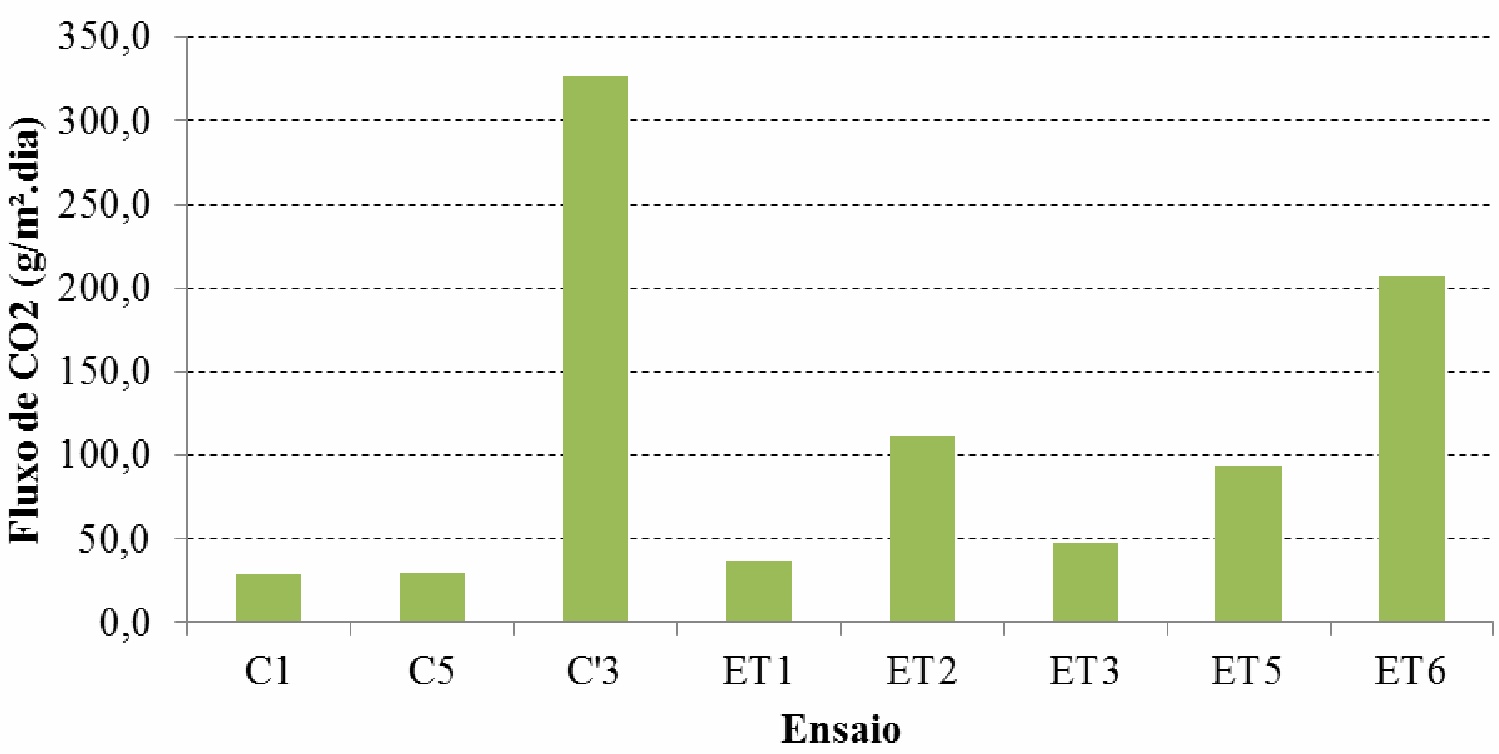

Figura 13: Fluxos de $\mathrm{CO}_{2}$ nos ensaios que não continham fissuras

Observa-se que tanto para os pontos que continham fissuras quanto para aqueles que não continham fissuras, os resultados encontrados para o fluxo de $\mathrm{CO}_{2}$ obedecem ao mesmo padrão que os verificados para o fluxo de $\mathrm{CH}_{4}$. 
Vale ressaltar que mesmo na inexistência de fissuras nas camadas de cobertura, os ensaios realizados apresentaram emissões de $\mathrm{CH}_{4}$ e $\mathrm{CO}_{2}$. Esta observação pode ser explicada devido ao fato de que os solos empregados nas camadas de cobertura apresentaram alto teor de areia em sua composição. Joaquim Jr. (2015) pesquisou a condutividade hidraúlica do solo saturado $\left(\mathrm{K}_{\text {sat }}\right)$ em laboratório dos solos "A" e "B"das camadas convencionais e obteve resultado de $4,84 \times 10^{-6} \mathrm{~m} / \mathrm{s}$ para o solo "A" e $7,90 \times 10^{-6} \mathrm{~m} / \mathrm{s}$ para o solo "B". Estes valores indicam que os gases têm condições de migrar através dos vazios existentes nos solos. Observa-se ainda que o sistema de captação do biogás era passivo na área de estudo.

A cobertura evapotranspirativa ficou livre dos problemas relacionados às fissuras, o que representou sua principal vantagem. Outro benefício desta cobertura residiu na estrutura da superfície do solo. Observouse que a vegetação atuou beneficamente na construção de uma estrutura coesa entre o solo e às raízes da grama. Esta estrutura apresenta maior resistência ao escape do biogás. A Figura 14 apresenta a condição do solo sob as raízes da vegetação que evidencia uma espessura significativa de solo aderido na região do sistema radicular da grama.
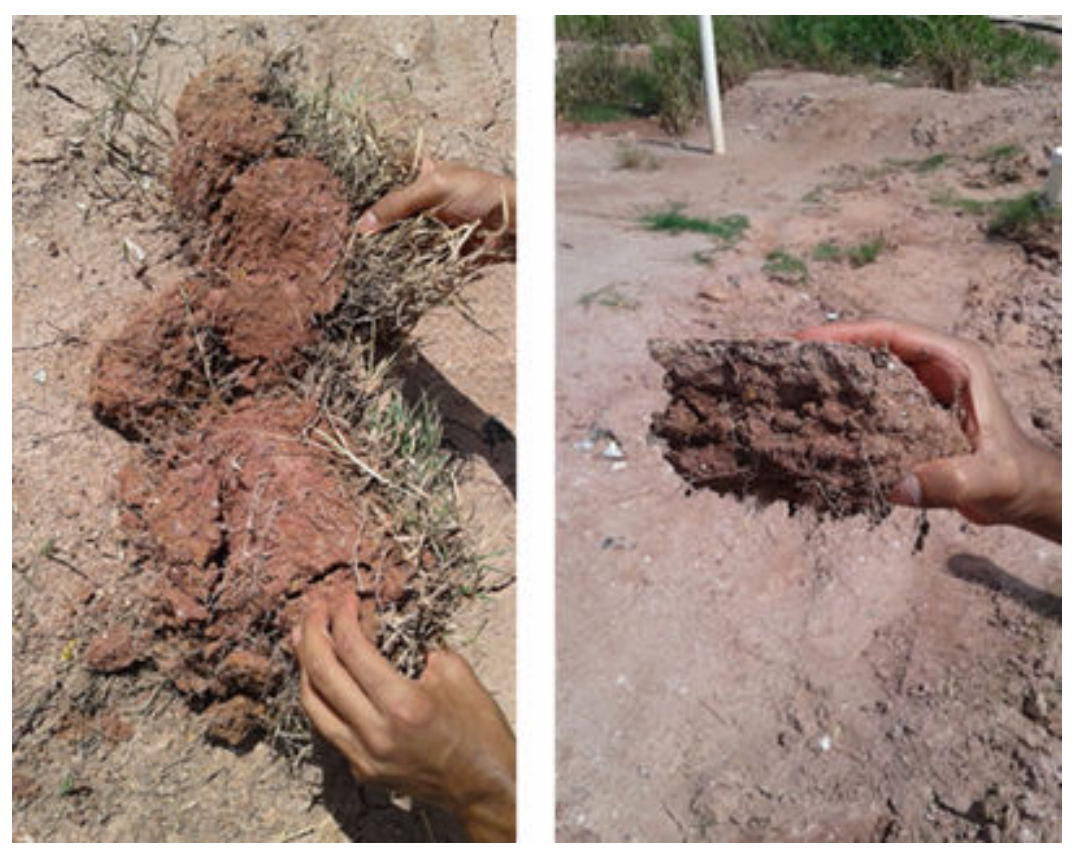

Figura 14: Estrutura do solo sob as raízes da camada evapotranspirativa. Fonte: Joaquim Jr. (2015)

Nos dias 13/11/2014, 16/12/2014 e 03/02/2016 foram realizados ensaios de placa de fluxo em cada uma dos 3 tipos de camadas de cobertura e, os resultados encontrados para o fluxo de $\mathrm{CH}_{4}$ nesses ensaios são apresentados na Figuras 15. 


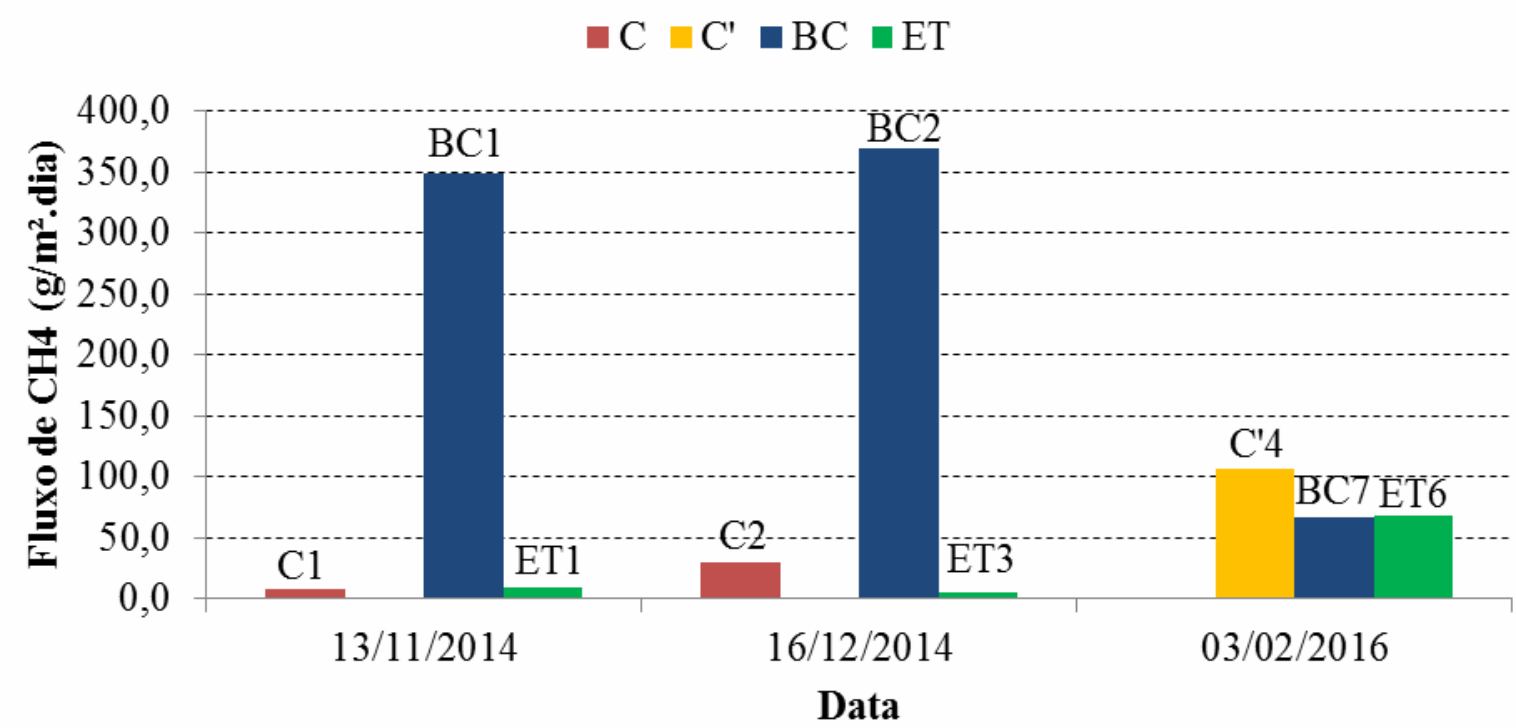

Figura 15: Fluxo de $\mathrm{CH}_{4}$ nos ensaios realizados no dia 13/11/2014, 16/12/2014 e 03/02/2016

A análise revela que nos dias 13/11/2014 e 16/12/2014, os ensaios realizados na camada de barreira capilar apresentaram valores elevados. Uma justificativa para tais resultados é a profundidade da fissura presente nos pontos $\mathrm{BC} 1$ e $\mathrm{BC} 2$, conforme mencionado anteriormente. Já para o dia 03/02/2016 temos que o ponto C'4 apresentou fluxo mais elevado do que os pontos BC7 e ET6. Os pontos BC7 e C'4 tiveram suas fissuras caracterizadas como pequenas.

Os resultados encontrados para o fluxo de $\mathrm{CH}_{4}$ na camada convencional com solo "A" mostraram-se ser pontuais para a área na qual se encontra esta célula experimental. Mesmo tendo sido determinado um grau de compactação de $92 \%$ nesta célula, esses resultados com baixos valores encontrados para o fluxo de $\mathrm{CH}_{4}$ nesta camada devem ser considerados com cautela. Independentemente da existência ou não de fissuras, os ensaios realizados na atual pesquisa na camada convencional com solo "A" apresentaram valores muito reduzidos. Borba (2015) realizou estudo na mesma camada de cobertura do aterro sanitário, porém em outros locais fora do perímetro da célula experimental e, apresentou resultados para o fluxo de $\mathrm{CH}_{4}$ que variaram de 181,0 a $575,0 \mathrm{~g} / \mathrm{m}^{2}$.dia para ensaios realizados em pontos com fissuras e de 0,1 a $59,5 \mathrm{~g} / \mathrm{m}^{2}$.dia para os pontos sem fissuras. Possivelmente estes resultados revelam uma especificidade da célula experimental em estudo, não representando a realidade das emissões de biogás normalmente encontradas neste sistema de cobertura. Mariano (2008) encontrou valores que variaram de 0 a $401,0 \mathrm{~g} / \mathrm{m}^{2}$.dia para o fluxo de $\mathrm{CH}_{4}$ na camada convencional do Aterro Controlado de Aguazinha - PE com sistema de extração passivo de biogás. Fernandes (2009) encontrou valores que variaram de 23,3 a $337,7 \mathrm{~g} / \mathrm{m}^{2}$.dia para o fluxo do mesmo gás na camada convencional instalada no Aterro Experimental de Belo Horizonte - MG com sistema de biogás passivo. Em Lopes (2011), as variações encontradas foram ainda maiores, sendo de $2,1 \mathrm{a} 984,7 \mathrm{~g} / \mathrm{m}^{2}$.dia para o fluxo de $\mathrm{CH}_{4}$ em camada convencional instalada em célula experimental no Aterro da Muribeca - PE também com sistema de extração de biogás passivo. 

estudadas.

A Tabela 2 apresenta os fluxos médios de $\mathrm{CH}_{4}$ e $\mathrm{CO}_{2}$ em cada uma das camadas de cobertura

Tabela 2: Fluxos médios de $\mathrm{CH}_{4}$ e $\mathrm{CO}_{2}$ nas camadas de cobertura

\begin{tabular}{ccc}
\hline $\begin{array}{c}\text { Tipo de Camada de } \\
\text { Cobertura }\end{array}$ & $\begin{array}{c}\text { Fluxo Médio de } \mathbf{C H}_{\mathbf{4}} \\
\left(\mathbf{g} / \mathbf{m}^{2} . \text { dia) }\right.\end{array}$ & $\begin{array}{c}\text { Fluxo Médio de } \mathbf{C O}_{\mathbf{2}} \\
\mathbf{( g / \mathbf { m } ^ { 2 } . \mathbf { d i a } )}\end{array}$ \\
\hline C & 13,9 & 58,6 \\
C' & 166,3 & 394,2 \\
BC & 142,5 & 376,2 \\
ET & 35,2 & 99,3 \\
\hline
\end{tabular}

Os fluxos médios de $\mathrm{CH}_{4}$ na camada convencional (C') e na barreira capilar foram de $166,3 \mathrm{~g} / \mathrm{m}^{2}$.dia e $142,5 \mathrm{~g} / \mathrm{m}^{2}$.dia respectivamente. Esses resultados evidenciam que ambas as coberturas não tiveram desempenho satisfatório na minimização das emissões de biogás para a atmosfera.

O fluxo médio de $\mathrm{CH}_{4}$ na camada convencional (C) foi de $13,9 \mathrm{~g} / \mathrm{m}^{2}$.dia. Borba (2015) apresentou uma taxa de emissão média de $77,6 \mathrm{~g} / \mathrm{m}^{2}$.dia para o $\mathrm{CH}_{4}$. Abichou et al. (2006) encontrou uma emissão média de $53,6 \mathrm{~g} / \mathrm{m}^{2}$.dia para um aterro sem sistema de extração de biogás.

Considerando este resultado pontual encontrado na célula experimental da camada convencional, as demais medidas de emissões indicam que a camada evapotranspirativa apresentou melhor desempenho na minimização da emissão do biogás para a atmosfera.

\section{CONCLUSÕES}

Os solos empregados nas camadas de coberturas apresentaram características granulares inadequadas (alto teor de areia) para a minimização das emissões fugitivas de biogás.

A cobertura do tipo convencional e a barreira capilar apresentaram danos por ressecamento (fissuras). Já a cobertura evapotranspirativa apresentou vantagem por ficar livre dos problemas relacionados às fissuras, além de atuar de forma eficaz na construção de uma estrutura que contribui para a retenção do biogás.

As emissões de $\mathrm{CH}_{4}$ nos ensaios realizados em pontos com fissuras foram maiores do que aqueles realizados em pontos sem fissuras.

Apesar da depreciação da vegetação, a camada evapotranspirativa proporcionou melhor desempenho em relação às demais camadas de cobertura, apresentando variação de 5,0 a $68,9 \mathrm{~g} / \mathrm{m}^{2}$.dia para as emissões de $\mathrm{CH}_{4}$.

Os resultados indicaram que as emissões de biogás na camada convencional com solo "A" variaram de 7,5 a $29,9 \mathrm{~g} / \mathrm{m}^{2}$.dia para o $\mathrm{CH}_{4}$. Borba (2015) apresentou resultados para o fluxo de $\mathrm{CH}_{4}$ na mesma camada de cobertura de até $575,0 \mathrm{~g} / \mathrm{m}^{2}$.dia, o que indicou que os baixos valores encontrados para o fluxo de $\mathrm{CH}_{4}$ nesta camada se referiu a uma especificidade da célula experimental estudada. 


\section{REFERÊNCIAS BIBLIOGRÁFICAS}

ABICHOU, T.; CHANTON, J.; POWELSON, D.; FLEIGER, J.; ESCORIAZA, S.; YUAN, L.; STERN, J. Characterization of Methane flux and oxidation at Solid Waste landfill covers. Journal of Environmental Engineering. Feb. p. 220-228, 2006.

BORBA, P. F. S. Avaliação das emissões de GEE e BTEX em aterro sanitário de grande porte. 2015. $135 \mathrm{f}$. Dissertação (Mestrado em Engenharia Ambiental) - Faculdade de Engenharia, Universidade do Estado do Rio de Janeiro, Rio de Janeiro, 2015.

CABRAL, A. R.; EL-GHABI, B.; PARENT, S-É.; MARINEAU, L. Design and performance of an experimental double capillary barrier cover placed. In.: Proceedings Sardinia, $11^{\circ}$ International Waste Management and Landfill Symposium, S. Margherita di Pula, Cagliari, Italy, 2007.

CZEPIEL, P. M.; MOSHER, B.; CRILL, P. M.; HARRISS, R. C. Quantifying the effect of oxidation on landfill methane emissions. Journal of Geophysical Research, v. 101, n. D11, p. 16.721-16.730, 1996.

FERNANDES, J. G. Estudo da emissão de biogás em um aterro sanitário experimental. 2009. $101 \mathrm{f}$. Dissertação (Mestrado em Engenharia Ambiental) - Escola de Engenharia, Universidade Federal de Minas Gerais, Minas Gerais, 2009.

JOAQUIM JUNIOR, G. O. Comparação de desempenho de sistemas de cobertura em relação à infiltração de água pluvial no aterro sanitário de Seropédica (RJ), durante a fase de operação. 2015. 215 f. Tese (Doutorado em Ciências) - Escola de Química, Universidade Federal do Rio de Janeiro, Rio de Janeiro, 2015.

LOPES, R. L. Infiltração de água e emissão de metano em camadas de cobertura de aterros de resíduos sólidos. 2011. 250 f. Tese (Doutorado em Engenharia Civil) - Programa de Pós-Graduação em Engenharia Civil, Universidade Federal de Pernambuco, Recife, 2011.

MACIEL, F. J. Estudo da geração, percolação e emissão de gases no aterro de resíduos sólidos da Muribeca/PE. 2003. 173 f. Dissertação (Mestrado em Engenharia Civil) - Centro de Tecnologia e Geociências, Universidade Federal de Pernambuco, Recife, 2003.

MARIANO, M. O. H. Avaliação da retenção de gases em camadas de cobertura de aterros de resíduos sólidos. 2008. 243 f. Tese (Doutorado em Engenharia Civil) - Centro de Tecnologia e Geociências, Universidade Federal de Pernambuco, Recife, 2008.

OLIVEIRA, A. C. E. Diagnóstico e avaliação de emissões fugitivas de biogás na camada de cobertura final da central de tratamento de resíduos de Nova Iguaçu e do lixão de Seropédica, Rio de Janeiro. 2013. $142 \mathrm{f}$. Dissertação (Mestrado em Engenharia Ambiental) - Faculdade de Engenharia, Universidade do Estado do Rio de Janeiro, Rio de Janeiro, 2013.

PARK S.; LEE, C.; RYU, SUNG, K. Biofiltration for Reducing Methane Emissions from Modern Sanitary Landfills at the low methane generation stage. Water Air Soil Pollute. v. 196, p. 19-27, 2009.

TCHOBANOGLOUS, G.; THEISEN, H.; VIGIL, S. A. Integrated Solid Waste Management - Engineering principles and management issues. MCGraw-Hill International Editions, p. 978, 1993.

TEIXEIRA, C. E.; TORVES, J. C.; FINOTTI, A. R.; FEDRIZZI, F.; MARINHO, F. A. M.; TEIXEIRA, P. F. Estudos sobre a oxidação aeróbia do metano na cobertura de três aterros sanitários no Brasil. Eng. Sanit. Ambient., v. 14, n. 1, p. 99-108, 2009. 